\title{
Reproductive cloning, genetic engineering and the autonomy of the child: the moral agent and the open future
}

\author{
M Mameli
}

J Med Ethics 2007;33:87-93. doi: 10.1136/jme.2006.016634

Some authors have argued that the human use of reproductive cloning and genetic engineering should be prohibited because these biotechnologies would undermine the autonomy of the resulting child. In this paper, two versions of this view are discussed. According to the first version, the autonomy of cloned and genetically engineered people would be undermined because knowledge of the method by which these people have been conceived would make them unable to assume full responsibility for their actions. According to the second version, these biotechnologies would undermine autonomy by violating these people's right to an open future. There is no evidence to show that people conceived through cloning and genetic engineering would inevitably or even in general be unable to assume responsibility for their actions; there is also no evidence for the claim that cloning and genetic engineering would inevitably or even in general rob the child of the possibility to choose from a sufficiently large array of life plans.

Correspondence to: M Mameli, King's College, Cambridge, CB2 1ST, UK; gmm32@cam.ac.uk

Received 14 March 2006 Accepted 15 March 2006 n many countries there are laws prohibiting the use of cloning and genetic engineering as 1 methods of human reproduction. These laws are controversial. Commentators agree that coercive and state-directed uses of these reproductive technologies should be avoided. The controversy is about whether would-be parents should be allowed to use such technologies as tools (among others) for satisfying their reproductive desires.

Whether, when and how to reproduce are among people's most deeply held desires. They often have a central role in a person's selfconception, and the satisfaction or frustration of these desires has an important effect on our views about the quality and meaning of our life. Some authors have argued that we have a right to choose not only whether to have children or not but also when and by which method to have them, and that we should be allowed to use cloning and genetic engineering as reproductive methods if we wish to do so. ${ }^{1-4}$ Other authors claim that the extension of reproductive freedom to the use of these technologies is problematic, as it may interfere with the rights of those conceived through such methods. ${ }^{5}$

One popular argument against the human use of cloning and genetic engineering for reproduction is that these procedures are not "safe" and may result in the birth of children with severe developmental abnormalities. This argument shows (at most) that these biotechnologies should not be used for reproductive purposes until (through, say, experimentation on non-human animals and other experimental procedures) they become as reliable as other accepted reproductive methods. But some commentators maintain that would-be parents should not be allowed to use cloning and genetic engineering even when these procedures become developmentally safe. In their view, these technologies undermine the autonomy of the resulting child. Many versions of this objection exist and I shall discuss two different versions. According to the first version, the autonomy of cloned and genetically engineered people is undermined because knowledge of the method by which these people have been conceived make them unable to assume full responsibility for their actions. ${ }^{6}$ According to the second version, these biotechnologies undermine the autonomy of those conceived through such methods because they violate what Feinberg $^{7}$ calls their right to an open future. ${ }^{8}{ }^{9} \mathrm{I}$ shall offer reasons to believe that neither of these versions of the autonomy-of-offspring objection succeeds in showing that the human use of cloning and genetic engineering for reproduction should be banned or heavily restricted.

Before we start, some terminological and conceptual clarifications are needed. If would-be parents were allowed to use cloning and genetic engineering as reproductive methods, they would be given a tool for choosing the genes of their future children. Cloning allows would-be parents to give their children the same genes as a preexisting person, whereas genetic engineering allows them to give their children genes that have been intentionally designed, modified or selected in the laboratory for some particular purpose. I shall call those people conceived through cloning or genetic engineering g-people (and I shall only talk about people conceived through cloning or genetic engineering as a result of parental choice). I shall call genetic choices the choices by which parents can affect their children's genetic endowment. ${ }^{\mathrm{i}}$ I shall call environmental choices those choices by which parents can affect their children's developmental environment. Parents make environmental choices whenever they decide to educate their children according to a certain method, to

'Cloning and genetic engineering are not the only ways by which would-be parents can make genetic choices. Parents can affect the genetic endowment of their future children simply by choosing a particular reproductive partner rather than another. But obviously cloning and genetic engineering provide a much more direct and precise tool for affecting the genetic endowment of our children. 
make them do certain things and not others, to punish or reward them in certain ways, and so on.

Both genetic and environmental choices affect the phenotype of children, including the psychological phenotype. Every phenotypic trait (henceforth only trait) is the developmental outcome of the interaction between genetic and environmental factors. No trait is entirely genetically determined or entirely environmentally determined. Thus, both interventions affecting a child's genes and interventions affecting a child's environment can make a difference with respect to the child's phenotype. By ensuring that their children experience certain environments, parents can raise the probability that their children acquire certain desired traits. Similarly, by ensuring that their children have certain genes, parents can-at least in principle, assuming that genetic science becomes sufficiently advanced-increase their children's chances of developing certain desired traits. But different developmental factors, whether genetic or environmental, affect development in different ways. This means that in some cases the most reliable and practical way to increase the chances of a trait developing may consist in a specific genetic intervention, whereas in other cases it may consist in a specific environmental intervention, and in still other cases both kinds of interventions may be required. ${ }^{10}$

\section{THE MORAL AGENT}

One influential version of the autonomy-of-offspring objection to the use of cloning and genetic engineering for human reproductive purposes has been elaborated by Habermas. ${ }^{6} \mathrm{He}$ argues that g-people would be unable to conceive of themselves as the "undivided author" (pp 63-67) of their lives and, as a consequence, would be unable to assume full responsibility for their actions. Once informed about the way they were conceived, g-people would inevitably come to believe that the responsibility for their actions falls not on them but on their parents. This belief would undermine the autonomy of the person and his or her status as an "equal member of the moral community" (pp 42, 78).

In Habermas's view, in order to be a full member of the moral community, one must be able to conceive of oneself as full members of the moral community. For this to happen, one must be able to assume full responsibility for one's actions in the same way and to the same extent as other full members of the moral community do. But, according to Habermas, ${ }^{6}$ gpeople would inevitably believe that they are not responsible for their actions, at least not in the same way and to the same extent as are those conceived in standard ways. As a consequence, g-people would fail to interact with people conceived through standard reproductive methods "on an egalitarian basis" and would be condemned to "fatalism and resentment" (p 14). ${ }^{\text {ii }}$ Many passages in Habermas's book suggest that g-people's belief that they are not fully responsible for their actions would be true: g-people really are less responsible for their actions than are people conceived through standard methods.

The actions of any agent depend partly on the basic psychological makeup of the agent, which includes personality traits. Our genome has an important role in the development of our basic psychological makeup. By actually choosing to have a child with certain genes, the parents of a g-person can exercise an influence on the development of the basic psychological makeup of their child. Does this mean that their child is going to be less responsible for his or her actions than are other

iiHabermas talks mainly about genetically engineered people, but he also says that human clones would be in the same situation as genetically engineered people (pp 62-3). people? No one is fully responsible for his or her psychological makeup. Humans can, when they reach the age at which they are capable of conscious reflection, try to modify their psychological makeup, and sometimes these attempts are successful. At least sometimes, we can change our desires, emotional dispositions, habits, beliefs and even personality traits through conscious effort. This explains why we can in some circumstances be held responsible for cultivating or failing to cultivate our minds in one particular way or another. But people are not responsible for the psychological makeup they find themselves with at the age at which they become capable of conscious reflection. If full responsibility for our action requires that we be fully responsible for our psychological makeup, then obviously no one can be fully responsible for his or her actions. Thus, the fact that g-people are not fully responsible for their psychological makeup cannot be used to argue that they are less responsible for their actions than are people conceived through coital means.

Habermas does not endorse the view that people can be fully responsible for their actions only if they are fully responsible for their psychological makeup. Instead, his view seems to be that we can be fully responsible for our actions only if our basic psychological makeup is not the desired outcome of someone else's choice. If some features of a person's psychological makeup result from the random mixing of parental chromosomes-as is the case in humans conceived through coital means-the person's capacity to be morally responsible for his or her actions is not threatened. It is only when some of the fundamental psychological features of a person are the intended result of another person's choice that the threat exists. Thus, if a person behaves in a certain way (partly) because he or she has certain psychological dispositions, and if those dispositions (partly) due to a parental choice of genes designed to bring about those dispositions, then this person is not fully responsible for his or her behaviour. Part of the responsibility for the actions of a person falls on the parents and it does in a way make this person less responsible for his or her actions than are people conceived through standard methods.

The problem with this view is that many of the fundamental psychological features of virtually any person-including those conceived through coital means-are the desired outcome of someone else's choice. In particular, many of the fundamental psychological features of almost everyone are the desired outcome of parental environmental choices. Parents often make environmental choices aimed at influencing and directing their children's psychological development and at raising the probability that their children acquire certain emotional dispositions, desires, values, cognitive skills, personality traits and so on. Such parental efforts are often successful, even though not nearly as often as parents would like. Children often do acquire at least some of the psychological traits that their parents desire to see in them and they acquire these psychological traits partly as a result of their parents wanting their children to develop these traits. For example, a child may acquire an altruistic disposition partly as a result of his or her parents' wanting their child to be an altruistic person.

The fact that the psychological makeup of g-people is partly the desired outcome of parental choices cannot possibly entail that g-people are less morally responsible for their actions than are people conceived through standard methods, as the psychological makeup of standard people is also (usually) partly the desired outcome of parental choices. The only difference is that in the case of g-people the relevant parental choices include genetic choices, whereas in the case of people conceived through standard means they do not. Why should 
this difference matter? Habermas argues that the difference is morally important in relation to the violation of autonomy. According to him, environmental choices are "revisable" or "reversible", whereas genetic choices are not (pp 14, 62-64). Adults or adolescents can-through what Habermas calls a revisionary learning process ( $\mathrm{p} 62$ ) - rid themselves of the effects that their parents' environmental decisions have produced on their minds, or alternatively, they can endorse their parents' environmental choices. In contrast, g-people cannot rid themselves of the effects that their parents' genetic choices have had on them: they have no option but to accept such effects and thereby they cannot but see their parents' genetic choices as an alienating imposition.

Such a picture of psychological development is flawed. Biologists and psychologists have shown that many environmental effects on psychological development are irreversibleand this applies in particular, but not exclusively, to environmental effects that occur in early childhood-and they have shown that many genetic effects on psychological development are reversible. ${ }^{11}{ }^{12}$ With respect to the reversibility of effects, there is no general asymmetry between genetic and environmental choices. Thus, we can appeal to no such asymmetry to argue that people whose genome has been chosen are less responsible for their actions than those conceived through standard means.

Sometimes Habermas suggests that what really matters in relation to the autonomy of g-people is the moral selfunderstanding of these people and not whether such selfunderstanding is accurate: what matters is that g-people would believe that they are not responsible for their actions (p 53). ${ }^{4}$ Even if unjustified, this disavowal of responsibility would undermine their autonomy. It would lead them to see themselves as defective moral agents and would constitute a "pre-natally induced self-devaluation" (p 81), a self-devaluation induced by the parents' decision to actively choose their children's genes. Such self-devaluation would make decisionmaking difficult for g-people and encourage other members of society to treat g-people as less than full moral agents. G-people would be denied (implicitly or explicitly) full membership of the "moral community of equals" and their participation in society would be unjustly restricted. This, says Habermas, is sufficient to show that would-be parents should not be allowed to use genetic engineering and cloning as reproductive methods.

Various replies to arguments of this kind have been elaborated. Some authors have claimed that a person's false beliefs cannot provide moral grounds for restricting another person's freedom. ${ }^{13}$ Others have appealed to some form of Parfit's non-identity principle. ${ }^{12}$ There is no room to discuss these proposals here. I want instead to explore what I believe is a better (even though not incompatible) reply. The claim that gpeople would inevitably come to believe that they are defective moral agents is wrong, or at least (at this stage) unsupported.

The costs of refusing to take responsibility are very high. As suggested by Habermas himself, the price to pay for the disavowal of responsibility for our actions is the exclusion from full participation in society. Given this, a very strong incentive would exist for g-people to assume full responsibility for their actions and to present themselves to other members of society as full moral agents deserving all the privileges (but also all the duties) of full members of society. In a different (but related) context, Dennett ${ }^{14}$ says something relevant:

Aren't we headed toward a 100 percent 'medicalized' society in which nobody is responsible, and everybody is a victim of one unfortunate feature of their background or another (nature or nurture)? No, we are not [...] People want to be held accountable. The benefits that accrue to one who is a citizen in good standing in a free society are so widely appreciated that there is always a presumption in favor of inclusion. Blame is the price we pay for credit, and we pay it gladly under most circumstances. We pay dearly, accepting punishment and public humiliation for a chance to get back in the game after we have been caught out in some transgression. (p 292)

The benefits resulting from the assumption of full responsibility for our actions are likely to be sufficient to hold the line against what Dennett calls "the spectre of creeping exculpation". Dennett was not thinking about g-people when he wrote this passage, but it is not difficult to see that what he says applies to g-people too. On this view, g-people would not in general believe that they are defective moral agents. They would not believe this because they would in general be aware of (or they would learn very quickly about) the disadvantages that such belief brings with it.

It is undoubtedly true that, if the human use of cloning and genetic engineering as reproductive methods were to become legal, some g-people would sometimes be tempted to argue that some of their actions-the socially undesirable ones-are not their fault but their parents' fault. This by itself does not show that would-be parents should not be allowed to choose the genes of their future children. After all, people conceived through standard means are sometimes tempted to disavow responsibility for some of their actions (again, the socially undesirable ones) and to claim that the responsibility for such actions falls on their parents and on their parents' educational choices. Yet, we do not normally take this as a reason for prohibiting parents in general from choosing how to educate their children.

If the benefits associated with the assumption of full responsibility turned out to be insufficient to hold the line against the spectre of creeping exculpation (or perhaps in this case we should call it the spectre of creeping self-devaluation), we could do something about it. We could start teaching people from an early age that some of a person's traits are the result of his or her parents trying - through genetic or environmental means-to raise the chances of those traits developing and that this does not (at least not by itself) in any way affect the moral status of this person. We could also make sure that people have a good understanding of what they give up-that is, full participation in society-if they disavow responsibility for their actions through the kind of moral self-devaluation described by Habermas. And so on. We could perhaps even argue that if, despite all this, some g-people still chose to self-devalue their moral status, the blame for such self-devaluation would have to be assigned to these people themselves and not to their parents or to the fact that society allows parents to determine the genes of their children.

But what if the kind of moral self-devaluation that Habermas has in mind is similar to certain forms of depression? Some forms of depression cannot be cured or avoided by making people aware of the fact that their being depressed is unjustified and irrational and that there are high costs attached to being depressed. Could not the same be true of habermasian self-devaluation? In some cases, the process leading to the state of depression is (or involves) a reasoning process. In other cases, the depression is due (merely) to organic causes. In the latter cases, it is not possible to avoid the emergence of the depression by making the person realise that it would be irrational or disadvantageous for him or her to become depressed. But habermasian self-devaluation is not due (merely) to organic causes. It is the outcome of a reasoning process: it emerges when a g-person applies an incorrect view of 
genes, parental choice and moral agency to himself or herself. Given this, to see whether the analogy is correct, we need to focus only on those cases in which the depression results from a reasoning process.

Consider the following situation: A person starts thinking about her life and after careful consideration she concludes (perhaps correctly, perhaps incorrectly) that she has reasons to believe that her life is going very badly. She adopts the belief that her life is going very badly, this belief makes her depressed and the depression makes her very unlikely to revise the bleak view she has of her life. Once the depression kicks in, telling this person (or even making her realise) that her being depressed is unjustified and irrational has basically no effect on her depression. But as the depression is (partly) the result of a reasoning process, the depression could have been avoided by giving the person reasons to reject the adoption of the belief that her life was going very badly. After all, many people refuse to believe that their life is going very badly (even when they have good evidence for the truth of this belief) and probably (conscious or unconscious) knowledge about the costs attached to being depressed has a role in this.

Let us apply this to habermasian self-devaluation. Perhaps, when people start self-devaluing their moral agency in the way suggested by Habermas, it becomes very difficult for them to stop self-devaluing themselves, and showing them that their self-devaluation is unjustified and irrational has basically no effect on them. This may be the case, even though, at the moment, we have no evidence for it. But let us suppose, for the sake of argument, that habermasian self-devaluation has the effects just described. Even on this supposition, we can still hold the line against the spectre of creeping self-devaluation. We can do this by making sure that g-people in general do not acquire the belief that they are defective moral agents. We can teach them (from an early age) the correct way of thinking about genes, parental choice and moral responsibility, and we can explain to them (from an early age) the disadvantages and the irrationality of moral self-devaluation.

All I have said so far is of course compatible with the claim that would-be parents can in principle use cloning and genetic engineering to make their children unable (when they grow up) to take responsibility for their actions: they could use these biotechnologies in ways that cause their children to actually (and inevitably) develop into defective moral agents. They could choose for their children genes that interfere with the development of the mental abilities required for full-blown intentional action and for moral reasoning. For example, they could choose genes that make their children severely mentally handicapped. Such parents would intentionally make their children disabled. Arguably, their action would constitute an abuse and would have to be punished accordingly. But the (remote) possibility of such misuses does not (by itself) provide support for general restrictions on the reproductive use of genetic engineering and cloning. This is shown by the fact that parents can of course interfere with the cognitive and emotional development of their children through perverse and abusive environmental interventions, interventions that can result in their children becoming defective moral agents. This can happen, for example, in the case of parents who interfere with the development of their children's brain by giving them powerful addictive drugs, by beating them violently or by keeping them as recluses for many years. We do not normally take the relatively rare occurrences of abuses of this sort as a reason to ban parents in general from choosing how to bring up their children. Similarly, we should not take the remote possibility that some parents may misuse cloning and genetic engineering in the ways described as a reason to ban the reproductive use of these technologies.

\section{THE OPEN FUTURE}

In this section, I want to discuss another version of the autonomy-of-offspring objection. This version appeals to what Feinberg $^{7}$ calls "the right to an open future" and has been elaborated by various authors. For example, Davis ${ }^{8}$ claims that reproductive cloning violates the child's right to an open future, especially in cases where the child is brought to life with the explicit intention of creating someone who resembles as much as possible a pre-existing person. Buchanan et al argue that reproductive genetic engineering can, in some circumstances, infringe a child's right to an open future and that this fact should seriously be taken into account when deciding whether to ban this reproductive technology.

What is the right to an open future? It is not easy to extract a single definition from Feinberg's original article. Buchanan et al suggest that the best way to make sense of Feinberg's notion is as follows:

The idea is that parents have a responsibility to help their children during their growth to adulthood to develop capacities for practical judgement and autonomous choice, and to develop as well at least a reasonable range of the skills and capacities necessary to provide them the choice of a reasonable array of different life plans available to members of their society. [...] In this view, it would be wrong for parents to close off most opportunities that would otherwise be available to their children in order to impose their own particular conception of the good life. $(\mathrm{p} 170)^{9}$

Feinberg's original article is about parents' environmental rather than genetic choices. ${ }^{7}$ The case discussed is the one of Wisconsin $v$ Yoder. In the early 1970s, parents belonging to the Amish community asked to be allowed to withdraw their children from school at the age of 14 years, 2 years before the age at which any child can withdraw from school on his or her own. They argued that schooling beyond age 14 is not necessary for the Amish way of life and interferes with Amish children acquiring the skills and motivation needed to become an integrated member of the Amish community. The Wisconsin Supreme Court accepted their request. Feinberg argues that, had the Amish asked to withdraw their children from school 4 or 6 years before the age at which other children can withdraw, their request would have been illegitimate. An Amish child who undergoes 4 or 6 fewer years of schooling than is required by non-Amish children would almost certainly end up being unfit for any way of life other than the Amish one. The child would not develop the skills necessary to pursue life projects different from those that can be pursued as a member of the Amish community. Because of competition with other members of society, this person would not have any real chance of pursuing non-Amish life projects with some probability of success. Thus, this educational choice would rob this person of the possibility of choosing from a "reasonable array of life plans".

According to Buchanan et al, ${ }^{9}$ the principle that parents should not be allowed to make choices resulting in their children not having a reasonable array of life plans from which to choose should be applied to both environmental and genetic choices. Thus, a genetic intervention that makes a child particularly fit to pursue a career as, say, a pianist but unfit to pursue any other (available) career, would be illegitimate, especially in contemporary Western societies where a relatively large range of choices is usually available to most people. Genetic interventions that make children fit for only a restricted range of ways of life violate the right to an open future and should thereby be banned. 
The ability to choose our own life plan is arguably one of the essential conditions of the good life. What does this ability require? People must have cognitive and emotional skills that make them able to (a) compare (consciously or unconsciously) different life plans, (b) select one among those life plans they are able to consider, (c) transform this choice into the intention to behave in accordance with the chosen plan and (d) transform this intention into behaviour that actually conforms to the chosen option. Moreover, people must have skills that allow them to pursue different life plans with some definite chance of success, and they must be in a social context where these different life plans can actually be pursued. If people have skills that make them fit for one and only one particular and very specific life plan, they cannot be said to actually be able to choose their own life plan. Despite their decision-making abilities being normal, they have (in some sense) no choice. Similarly, if people live in a despotic society where they are allowed to pursue only one kind of career, they are obviously not free to choose their life plan.

Parents inevitably exert an important influence on the array of life plans available to their children. In many cases, this influence results in children having a larger array of life plans from which to choose than they would otherwise have had. In other cases, the influence results in children having a smaller array of life plans from which to choose than they would otherwise have had. Making someone fit for a particular life plan often (but not always) results in making the same person less fit for other life plans. Many parents make environmental choices aimed at increasing their children's chances of succeeding in the pursuit of more or less specific life plans. By doing so, they often make their children less likely to succeed in the pursuit of other (alternative) life plans and, in this sense, they may reduce the range of life plans available to their children. Yet this sort of parental behaviour is in most cases considered legitimate, and some see it as an inevitable ingredient of being a good parent. If the practice is legitimate in the case of (most) parental environmental choices, why should it not be legitimate in the case of (most) parental genetic choices? Parents are currently allowed to adopt relatively severe educational methods aimed at, for example, transforming their children into successful tennis players or into successful law school graduates. Given this, why should they not be allowed to use genetic methods to achieve similar results?

The discussion about the legitimacy of the Amish parents' request suggests that there is a moral limit to the extent to which parents can be allowed to reduce the array of life plans available to their children. If some environmental choices (eg, not sending a child to school) reduce the range of life plans available to a child below a certain threshold, then those choices can be said to violate the child's autonomy and are thereby illegitimate. Exactly the same applies to genetic choices. But what is the minimum size of a "reasonable array of life plans"? What is the threshold that parental choices-be they genetic or environmental-should never trespass? This is a difficult question and there is no room here for dealing with it properly. The correct answer to this question depends on many different factors. Buchanan et al, ${ }^{9}$ for example, argue that the answer depends, among other things, on what the correct theory of justice is.

Despite the question being a difficult one, we can examine current practice for some suggestions about how to think about this issue. For example, we may notice that there exist relatively large disparities in the range of life plans available to different members of society. Some of these disparities are due to unjust social arrangements, but arguably some of them are not. Rich people usually have more opportunities than poor people, and at least some of these differences in opportunity are usually not considered to be the result of unjust social arrangements. Yet it seems wrong to claim that, except perhaps in cases of extreme poverty, poor members of society violate their children's right to an open future when they decide to give birth to a child and not to give up their child for adoption to rich members of society. This suggests that if our current practices in this domain are correct, the morally permissible minimum size of a "reasonable array of life plans" - the size below which the child's right to an open future is violated-is relatively small and poor parents do not in general trespass the critical threshold.

Another consideration is that cloning and genetic engineering would probably not be used to reduce the array of life plans available to a child below the morally permissible threshold. Let us consider cloning first. In so far as the life plans available to children depend on their physical and mental abilities (rather than on factors extrinsic to the child, eg, the wealth of the parents or the structure of society) and in so far as such physical and mental abilities depend on the children's genome (rather than on their developmental environment), the array of life plans available to a cloned child is similar to the array of life plans available to the person from whom the child's genome is derived. Thus, unless the parents select for their child the genome of someone who, because of his or her genes, did not have a decent minimum number of different life plans from which to choose, the parental decision to conceive a child by cloning cannot (in general) interfere with the child's chances to have a reasonable array of life plans at his or her disposal. In fact, if the parents decide to create a child by cloning someone who had many options and opportunities in life, their choice will (in general) positively contribute to the range of life plans available to the child.

What about genetic engineering? Many would-be parents are likely to want to use genetic engineering to increase the probability that their children develop traits-such as high intelligence-which would make the children more likely to succeed in a whole range of different life plans. Such genetic choices would in general enlarge rather than reduce the array of life plans available to the future child. But some parents may want to use genetic engineering to increase the chances of their child becoming fit for a very specific life plan. In many cases, such genetic choices would reduce the range of life plans available to a child to the same extent as currently accepted environmental choices (such as the decision to make a child play a lot of tennis). In other cases, the genetic choices would reduce the range to the same extent as environmental choices that are currently considered illegitimate (such as the decision not to send a child to school at all). In so far as we can make sure that cases of the second kind are relatively rare, the possible occurrence of these cases cannot be used as a reason to ban the reproductive use of genetic engineering.

Parents can in principle use cloning and genetic engineering to make their children unable to choose their life plan. They could choose for their children genes that interfere with the normal development of the cognitive and emotional abilities required to compare and select life plans or they could choose for their children genes that are likely to make them fit only for a very specific life plan. It is for these reasons that, as in the case of parental environmental choices, parental genetic choices should be regulated and constrained. But they should be regulated and constrained in ways that are similar to the way in which environmental choices are regulated.

Another interpretation of the open-future objection needs to be discussed. Some commentators think that the array of life plans available to people depends not only on their skills and sociophysical context but also on the way with conceive of themselves and of the options available to them. According to these authors, cloned people who know what kind of life was 
lived by a pre-existing genetic twin (and what kind of choices the twin made) would feel that their destiny has already been written, that they are condemned to make choices that are similar to those of the twin, and that they are not really free to choose their own life plan. This feeling of pre-determination would be amplified by the interactions between the cloned person and other people. The parents in particular would have expectations about their child, expectations based on what they know about the pre-existing twin. Such expectations would exert a powerful psychological pressure on the cloned person and would heavily restrict the array of life plans effectively available to him or her. The cloned person would be condemned to live "a life in the shadow" of the pre-existing twin. ${ }^{8}{ }^{15-17}$ Some commentators have extended this argument to the case of genetically engineered people. In their view, genetically engineered people who know that their parents chose for them genes designed to bring about, say, a preference for a particular kind of career would feel heavily constrained in the kind of choices they can make, and parental expectations would amplify this feeling. ${ }^{18}$

As in one version of Habermas's objection to the human use of cloning and genetic engineering for reproduction, on this version of the open-future objection the threat to the autonomy of g-people is mainly due to the way g-people are supposed to conceive of themselves. My reply in this case is similar to my reply to Habermas. There is no good evidence for the claim that cloned people would inevitably or even in general see themselves as doomed to repeat the choices of their preexisting twins. Because of the disadvantages associated with the feeling of having one's destiny already written, it seems likely that they would often rebel against the thought that they have to approach life in the same way as their pre-existing twins. Perhaps they would try to differentiate themselves as much as possible from their pre-existing twins. Moreover, they would probably learn very quickly - by experimenting with their lives, by observing the behaviour of other clones or by reading about standard monozygotic twins-that they can make choices that differ considerably from those of their preexisting twins. We could also start teaching people from an early age that the fact that two people have the same genes does not imply that they are destined to live similar lives. We could in this way hold the line against the feeling of pre-determination and all the bad consequences that such feeling produces on one's options in life. Similar considerations apply, mutatis mutandis, to the case of genetically engineered people.

What about parental expectations? Would g-peoples' right to an open future be infringed by such expectations? No good evidence supports this claim either. Parental expectations often have an important and positive role in child development, even though they can occasionally harm a child and unjustly constrain his or her (future) freedom of choice. Arguably, this would apply to g-people in the same way that it applies to people conceived through standard methods. G-people would, when they reach maturity, be able to rebel against the expectations of their parents, or to endorse them if they wish to do so, and arguably they would be able to do this to the same extent as other people.

It should also be noticed that we currently accept very strong and pressing parental expectations as legitimate. Consider the example of the firstborn royal child, who has to cope not only with the expectations of the parents but also with the expectations of a whole nation and beyond: everybody expects the child to take the throne when the right moment comes. ${ }^{2}$ We do not usually see these expectations as a reason to prohibit kings and queens from having children. This suggests that we do not usually see such expectations as infringing on the royal child's right to an open future. If we do not want to revise our judgement in this case, we should not see the expectations of the parents of g-people-which in general would probably be less pressing than those concerning the royal child-as infringing on g-people's right to an open future either.

\section{CONCLUSIONS}

Some authors have argued that the human use of reproductive cloning and genetic engineering should be prohibited because these biotechnologies undermine the autonomy of the resulting child. In this paper, I have considered two versions of this objection. I have argued that there is no evidence that people conceived through cloning and genetic engineering would inevitably or even in general be unable to assume responsibility for their actions. And I have argued that there is no evidence that cloning and genetic engineering would inevitably or even in general rob the child of the possibility to choose from a sufficiently large array of life plans.

Some would-be parents may use cloning and genetic engineering in ways that violate the autonomy of their future child and, more generally, in ways that constitute abuse. But there seem to be no asymmetry between parental genetic choices and parental environmental choices with respect to the ways, the circumstances and, arguably, the frequency with which these choices would be used to perpetrate abuse. Thus, no such asymmetry can be appealed to in arguing that the restrictions on parental genetic choices (and on the biotechnologies that make such choices possible) should be much more severe than current restrictions on parental environmental choices. From a legislative viewpoint, genetic choices and environmental choices should be treated in similar ways.

Many issues remain unresolved. One issue concerns the best ways to avoid parents from using cloning and genetic engineering to perpetrate abuse. We also need to establish how to distinguish in a principled way between genetic interventions that constitute abuse and genetic interventions that do not. These issues are important, but they should be seen as special cases of general questions about the permissibility of producing certain kinds of effects on children, whether through genetic interventions or through environmental interventions. The fact that a given intervention affects a child's genome rather than his or her environment does not make that intervention more likely to constitute abuse. And the fact that an abuse has been perpetrated by a choice of genes does not make the abuse worse or its effects more irreversible than if it had been perpetrated through an intervention on the child's developmental environment.

We need to promote healthy and well-balanced relationships between parents and children and to reduce the risk of parental abuse, whether it is perpetrated by old means or by new technologies. A general ban on reproductive cloning and genetic engineering reduces the risk of these biotechnologies being used to perpetrate abuse, but it does so in a far-from-optimal and unjust way, by denying the use of these biotechnologies to many people who would use them in non-abusive ways and to satisfy some of their most fundamental desires.

\section{ACKNOWLEDGEMENTS}

I thank Lisa Bortolotti, John Harris and Tim Lewens for comments on previous versions of this article.

Competing interests: None.

\section{REFERENCES}

1 Harris J. Clones, genes and immortality. Oxford: Oxford University Press, 1998.

2 Harris J. On cloning. London: Routledge, 2004.

3 Agar N. Liberal eugenics. Oxford, UK: Blackwell, 2004.

4 Dworkin R. Sovereign virtue. Cambridge: Harvard University Press, 2000.

5 O'Neill O. Autonomy and trust in bioethics. Cambridge: Cambridge University Press, 2002. 
6 Habermas J. The future of human nature Cambridge, UK: Polity 2003

7 Feinberg J. The child's right to an open future. In: Aiken W, La Fallette H, eds. Whose child? Children's rights, parental authority and state power. Totowa, NJ: Littlefield, 1980.

8 Davis DS. Genetic Dilemmas. New York: Routledge, 2001

9 Buchanan A, Brock D, Daniels N, et al. From chance to choice. Cambridge: Cambridge University Press, 1999.

10 Mameli M. The inheritance of features. Biol Philos 2005;20:365-99.

11 Bateson P, Martin P. Design for a life. London: Jonathan Cape, 1999.

12 Marcus G. The birth of the mind. New York: Basic Books, 2004.

13 Brock D. Cloning human beings: an assessment of the ethical issues pro and con. In: Nussbaum MC, Sunstein CR, eds. Clones and Clones. New York: Norton, 1998.
14 Dennett D. Freedom evolves. New York: Viking, 2003

15 Holm S. A life in the shadow: one reason why we should not clone humans. Camb Q Healthc Ethics 1998;7:160-2.

16 Jonas $\mathbf{H}$. Biological engineering-a preview. In: Jonas $H$, eds. Philosophical essays: from ancient creed to technological man. Englewood Cliffs, NJ: Prentice Hall, 1974.

17 Report of the President's Council of Bioethics. Human cloning and human dignity, 2002.http://www.bioethics.gov/reports/cloningreport/index.html (accessed 12 Jun 2006)

18 Report of the President's Council of Bioethics. Beyond therapy: biotechnology and the pursuit of happiness, 2003.http://www.bioethics.gov/reports/ beyondtherapy/index.html (accessed 12 Jun 2006).

\section{CORRECTION}

doi: 10.1136/jme.2005.14738corr 1

Several errors occurred in the paper titled, Potential of embryonic stem cells: an ethical problem even with alternative stem cell sources (J Med Ethics;32:665-71). A fully corrected pdf is available online at http://jme.bmj.com/. The journal apologises for these errors. 